\title{
12
}

\section{Molecular Models for Semiconductor Particles}

\section{Luminescence Studies of Several Inorganic Anionic Clusters}

Thomas Türk ${ }^{1,2}$, Arnd Vogler ${ }^{1}$, and Marye Anne Fox ${ }^{2 *}$

${ }^{1}$ Department of Chemistry, Institut für Anorganische Chemie, Universität Regensburg D-8400 Regensburg, West Germany

${ }^{2}$ Department of Chemistry, University of Texas, Austin, TX 78712

In the transition region from a bulk semiconductor to a molecular cluster, the optical and photocatalytic properties of a semiconductor drastically change as the size of the crystallite is decreased. Several inorganic cluster molecules with a well-defined particle size and structure, (that is, $\mathrm{Zn}_{4}(\mathrm{SPh})_{10^{2-}}, \mathrm{Cd}_{4}(\mathrm{SPh})_{10^{2-}}$,

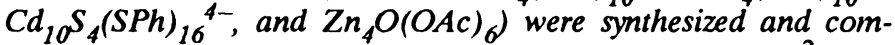
pared to the analogous mononuclear complexes $\mathrm{Zn}(\mathrm{SPh})_{4}{ }^{2-}$ and $\mathrm{Cd}(\mathrm{SPh})_{4}{ }^{2-}$. These clusters showed structured absorption spectra and a red-shift of their absorption edges with increasing crystallite size. The observed extinction coefficients suggest that the absorption bands can be best ascribed to ligand-to-metal charge-transfer (LMCT) transitions, which can be thought of as molecular cluster analogs of valence-to-conduction band transitions in bulk $\mathrm{ZnS}$ and CdS. Luminescence lifetimes and Stokes shifts provide further information about the nature of the optical transitions.

$\mathrm{T}_{\mathrm{H}}$ HE UTILITY OF SEMICONDUCTOR SUSPENSIONS as photocatalysts for the oxidative degradation of a wide range of organic compounds $(1,2)$

${ }^{*}$ Corresponding author

0065-2393/93/0238-0233\$06.00/0

(C) 1993 American Chemical Society 
derives from the collective versus molecular properties of the semiconductor cluster. Thus, band-gap excitation of the semiconductor cluster promotes an electron from the valence band to the conduction band and thereby generates an electron-hole pair that can be trapped by interfacial electron transfer. This species can then react with adsorbed species or exchange with lattice oxides to form other oxy radicals. Adsorbed oxygen acts as an effective electron trap, thus forming surface-bound superoxide. Many organic molecules or water can function as effective single-electron donors to trap a photogenerated hole. Subsequent reactions occurring between these redox-activated species or between these radical ions and other traps present in solution initiate oxygenation and oxidative cleavage, which ultimately lead to degradation and, in some cases, to complete mineralization.

The thermodynamics of these conversions is governed by the energetic positions of the valence and conduction bands. In both metal oxide and metal chalcogenide bulk semiconductor particles, the band positions are dependent on the medium; both bands shift $59 \mathrm{mV}$ per $\mathrm{pH}$ unit in aqueous solutions. In nonaqueous suspension, for example in acetonitrile, the band-gap positions can be specified on a standard electrochemical scale. For titanium dioxide, for example, the valence band edge lies at about $+2.4 \mathrm{~V}$ versus the saturated calomel electrode (SCE), and that for the conduction band lies at about $-0.8 \mathrm{~V}$. The potential for the conduction band is almost isoenergetic with the reduction potential of oxygen and thus permits facile electron trapping, but the valence band edge is highly oxidizing and thus permits single-electron oxidation of virtually any organic compound that bears either a lone pair or any conjugation.

The band gap of a given semiconductor is also dependent on particle size. The electronic properties of a given semiconductor cluster depend on the periodic arrangement of many atoms or molecules in a crystal lattice, and hence the shrinking diameter of a given semiconductor crystallite causes a gradual shift from a cluster exhibiting bulk semiconductor properties to one exhibiting well-spaced, discrete orbital levels. This phenomenon, referred to in the literature $(3-8)$ as size quantization, is accompanied by pronounced effects on both the optical characteristics and photocatalytic efficiency of the particles. As the cluster size becomes smaller and smaller, the band gap widens, with a dramatic blue shift from the absorption onset observed for the bulk particle.

A number of techniques have been employed to generate sizequantized clusters in stable environments. The in situ preparation of small clusters has been accomplished by the following techniques:

- ion exchange into spatially defined cavities such as polymers (9-12), vesicles $(13,14)$, and zeolites $(15-18)$ 
- surface modification by chemisorption or physisorption of capping reagents $(19-25)$

- biosynthesis (26)

- layer formation within Langmuir-Blodgett films (27)

- separation of size-disperse mixtures by size exclusion chromatography $(28-31)$

The in situ preparation methods are typically induced by ion exchange of the semiconductor cation into a defined cavity with cation-exchange ability $(32,33)$. Surface techniques can then be used to characterize both the phase of the crystallite (34) and the photocatalytic activity of the resulting included material (32).

By employing an ion-dilution technique, ultrasmall particles are formed by a method analogous to formation of an inverted micelle within a microemulsion (12). In this approach, the cation-to-ionomer cluster ratio is controlled by diluting the exchange solution with an inert ion, for example, $\mathrm{Ca}^{2+}$. The absorption onset for the resulting particles can be tuned over a range of more than $3 \mathrm{eV}$. Analogous spectral shifts are observed when layers of size-quantized particles, with dimensions smaller than $50 \AA$, are prepared by exposure of Langmuir-Blodgett films of cadmium arachidate to $\mathrm{H}_{2} \mathrm{~S}$ to yield semiconductor clusters of cadmium sulfide particles held within a lattice of layered arachidate anions (27). As in the clusters generated by ion-dilution of perfluorinated ionomer membranes (Nafion) (12), the onset of absorption of this layer is significantly blue-shifted from that of the bulk semiconductor.

Despite the utility of these techniques in forming small particle sizes, all nonetheless give a relatively broad particle size distribution, which complicates the quantitative correlation of the physical properties of the observed semiconductor cluster with particle size. This problem can be overcome if the synthesis of a monodisperse cluster incorporating the atomic subunits of semiconductor particles is undertaken. These synthetic clusters provide models for conventional semiconductors but possess a well-defined size and shape (35-39). We describe in this chapter our characterization of the optical and electrochemical properties of three cadmium benzenethiolate clusters (Türk, T.; Resch, U.; Fox, M. A.; Vogler, A., unpublished results) and two zinc benzenethiolate clusters (Türk, T.; Resch, U.; Fox, M. A.; Vogler, A., unpublished results) studied as a function of cluster size. We are particularly interested in characterizing the gradual transition from molecular to semiconductor properties, as had been attempted in our previous effort to characterize the photocatalytic activity and spectroscopy of heteropolyoxyanions in comparison with metal oxide clusters and powders (40). Thus, we undertook a search for parallel photocatalytic activity and optical similarities between these clusters and bulk semiconductor particles. 
The available crystal structures (37) of these metal chalcogenide clusters imply that they are reasonable molecular models for $\mathrm{CdS}$ and $\mathrm{ZnS}$ in that the coordination environments of both the metal and the sulfur atoms, as well the bond distances and angles, are similar to those observed in the bulk semiconductor. We seek in this study to determine whether the organic capped clusters may bear similar analogy to quantized inorganic clusters. This chapter compares the spectroscopic properties of more detailed studies of each of these families, which are as yet unpublished.

\section{Spectroscopy}

The absorption spectra of $\mathrm{Cd}(\mathrm{SPh})_{4}{ }^{2-}, \mathrm{Cd}_{4}(\mathrm{SPh})_{10}{ }^{2-}, \mathrm{Cd}_{10} \mathrm{~S}_{4}(\mathrm{SPh})_{16}{ }^{4-}$, $\mathrm{Zn}(\mathrm{SPh})_{4}{ }^{2-}$, and $\mathrm{Zn}_{4}(\mathrm{SPh})_{10}{ }^{2-}$ show characteristic absorption bands in the ultraviolet region (Türk, T.; Resch, U.; Fox, M. A.; Vogler, A., unpublished results). In the cadmium complex containing only one $\mathrm{Cd}$ atom, only a single symmetrical absorption band at $282 \mathrm{~nm}$ can be observed, whereas two overlapping bands are present for both the tetranuclear and decanuclear complexes, respectively, at 249 and $275 \mathrm{~nm}$ and at about 250 and $280 \mathrm{~nm}$. This additional band presumably derives from the existence of two types of thiolate ligands at bridging and terminal positions. The absorption of benzenethiolate itself $(\lambda=303 \mathrm{~nm}, \epsilon$ (molar absorptivity) $=13,600 \mathrm{M}^{-1} \mathrm{~cm}^{-1}$ ) appears at a position well-resolved from these bands. As has been shown for many oxyanions and carbanions, coordination at the negatively charged site with a metal or alkyl group typically induces a pronounced blue shift on the observable absorption band (41). The red shift observed for the decanuclear cluster similarly parallels that expected as a ligand-to-metal charge-transfer (LMCT), whereby metal association in the higher molecular weight complex causes a lowering of the metal-centered antibonding orbital. The assignment of this transition as a LMCT transition is also parallel to that expected for the semiconductor CdS, in which the valence band is largely composed of filled sulfide $3 p$ valence orbitals, whereas the conduction band is principally composed of empty Cd 5 s orbitals $(39,42)$.

Similar considerations also apply to the zinc complexes. For example, for $\mathrm{Zn}(\mathrm{SPh})_{4}{ }^{2-}$, the absorption band at $273 \mathrm{~nm}$ is presumably an intraligand transition, because simple monometallic zinc complexes (bound to halide or hydroxide ligands) have been so characterized $(39,43)$, presumably because the zinc $4 s$ orbital lies at too high an energy to be an accessible acceptor orbital for a LMCT transition. Although the energy of this level will come down somewhat in $\mathrm{Zn}_{4}(\mathrm{SPh})_{10}{ }^{2-}$, the transition observed is probably a composite of intraligand and LMCT transitions, as has been suggested for a tetranuclear zinc oxocluster $\mathrm{Zn}_{4} \mathrm{O}(\mathrm{OAc})_{6}(39)$. 


\section{Emission Spectra and Singlet Lifetimes}

The multinuclear cadmium complexes exhibit luminescence spectra that are independent of excitation wavelength. As with the absorption spectra, the emission of the decanuclear complex $\left(\lambda_{\max }=545 \mathrm{~nm}\right)$ is broad and red-shifted from that of the tetranuclear complex $\left(\lambda_{\max }=500 \mathrm{~nm}\right)$. The substantial Stokes shifts from the absorption maxima just discussed indicate that appreciable geometric distortion occurred upon photoexcitation. Large Stokes shifts have also been previously reported for other tetranuclear clusters of $\mathrm{d}^{10}$ metals $(39,44-47)$. Solid samples of the $\mathrm{Cd}_{4}$ and $\mathrm{Cd}_{10}$ powders similarly display intense, broad emissions, with lifetimes of approximately $1 \mathrm{~ms}$ at $77 \mathrm{~K}$ being obtained by transient diffuse reflectance spectroscopy. Unlike the emission observed in solution, these emissions are not ordered with respect to cluster size as would be predicted for a metal-to-ligand charge-transfer (MLCT) transition and are instead assigned as spectroscopically forbidden intraligand transitions. The much shorter lifetimes associated with the red shift of the emission band and with increasing cluster size for this complex in solution at room temperature allow differentiation of this emission (as an allowed MLCT band) from that observed in the solid state at low temperature.

Similarly, the mononuclear zinc complex gives no detectable emission, but the tetranuclear zinc complex shows weak luminescence at 360 $\mathrm{nm}$. The short lifetime of this emission ( $35 \mathrm{ps})$ permits its assignment as an allowed MLCT transition. The excitation spectrum for this emission does not parallel its absorption spectrum, a result further supporting the previous assignment of the direct absorption as deriving at least in part from intraligand transitions. As with the cadmium clusters, a large Stokes shift (almost $10,000 \mathrm{~cm}^{-1}$ ) argues for appreciable geometrical excited-state distortion that, as was mentioned with respect to the cadmium clusters, is consistent with a LMCT transition deriving from population of metal antibonding orbitals upon photoexcitation.

\section{Cluster Electrochemistry}

Both the oxidation and reduction peak potentials for the cadmium clusters are sensitive to cluster size. The oxidation peak potential shifts from $+0.88 \mathrm{~V}$ vs. SCE in acetonitrile for the mononuclear cluster to $+0.77 \mathrm{~V}$ for the tetranuclear cluster to $+0.68 \mathrm{~V}$ in the decanuclear cluster. Similarly, a reduction wave is absent from the mononuclear complex (lying more negative than $-2.8 \mathrm{~V}$ vs. the $\mathrm{Ag}-\mathrm{AgCl}$ electrode), whereas the tetranuclear complex shows a well-defined wave at $2.47 \mathrm{~V}$ and the decanuclear complex at $-2.02 \mathrm{~V}$. $\mathrm{Zn}(\mathrm{SPh})_{4}{ }^{2-}$ displays a broad oxidation wave at 
$+0.05 \mathrm{~V}$ vs. $\mathrm{Ag}-\mathrm{AgCl}$, whereas $\mathrm{Zn}_{4}(\mathrm{SPh})_{10}{ }^{2-}$ exhibits an oxidation peak potential at $+0.79 \mathrm{~V}$. Although both oxidative potentials are completely irreversible, their positions are seemingly strongly affected by cluster size in parallel to the effects observed in the cadmium clusters. Neither zinc cluster showed discernible reduction waves within the solvent window (at potentials less negative than $-2.8 \mathrm{~V}$ vs. $\mathrm{Ag}-\mathrm{AgCl}$ ).

\section{Formation of Charge-Transfer Complexes}

A 1:1 mixture of the multinuclear cadmium complexes with methyl viologen in acetonitrile results in the appearance of a new band at about 470 $\mathrm{nm}$ for the $\mathrm{Cd}_{4}$ complex and at $440 \mathrm{~nm}$ for the $\mathrm{Cd}_{10}$ complex. This blue shift seems to be related to the increasing anionic charge density in the resulting charge-transfer complex, as has been observed for bands formed between methyl viologen and electron-rich naphthalene derivatives (48). With the monomolecular cadmium cluster, no evidence for a stable ground-state charge-transfer complex was available from absorption spectroscopy, although the intense blue color of the reduced methyl viologen monocation radical was obvious upon mixing. Presumably the enhanced driving force for thermal electron transfer accounts for this observation.

A broad charge-transfer absorption band is also formed upon mixing in a 1:1 molar ratio $\mathrm{Zn}_{4}(\mathrm{SPh})_{10}{ }^{2-}$ and methyl viologen. The resulting band, centered at $445 \mathrm{~nm}$, could be bleached by flash laser excitation in which the reduced methyl viologen radical, absorbing at $395 \mathrm{~nm}$ and 605 nm (49), was obvious.

\section{Photosensitivity of the Clusters}

UV illumination of any of the cadmium clusters causes disappearance of the UV absorption bands as a new broad emission band at 355 and a shoulder at $440 \mathrm{~nm}$ appear. Neither the rate nor the spectral shape of this new emission band is sensitive to oxygen. The rate at which the bleaching occurred was, however, dependent on cluster size, and the degradation of the mononuclear cluster occurs about 5 times as fast as the tetranuclear cluster, which decomposed about twice as fast as the $\mathrm{Cd}_{10}$ cluster. Mass spectroscopic analysis shows a product distribution consistent with the formation of thianthrene, benzothiophene, and benzenethiol. Completely parallel reactivity is observed with the zinc clusters, with a strong bleaching of the absorption band occurring upon UV radiation, while an 
intensely luminescent band appears with a maximum at 355 and shoulder at $440 \mathrm{~nm}$. $\mathrm{Cd}(\mathrm{SPh})_{4}{ }^{2-}$ is roughly 10 times more photosensitive than the tetranuclear cluster. As with the zinc clusters, the rate of the photobleaching is independent of the presence of oxygen, and the same distribution of photoproducts, as indicated by gas chromatography-mass spectrometry, was obtained upon photolysis of these clusters as with band-gap irradiation of a CdS suspension in the presence of an acetonitrile solution of benzenethiol.

\section{Conclusions}

Increasing cluster size in the $\mathrm{Zn}_{n}$ and $\mathrm{Cd}_{n}$ anionic clusters bearing benzenethiolate ligands causes shifts in their absorption spectra that reflect increasing LMCT character. Substantial Stokes shifts observed in the multinuclear clusters are consistent with appreciable excited-state geometrical distortion. Electrochemical oxidation and reduction peak potentials are also size-dependent, the oxidations and reductions becoming easier with increasing cluster size. Charge-transfer complexation of the multinuclear complexes with methyl viologen indicates enhanced redox activity. Photosensitivity of the complexes is also consistent with enhanced LMCT with a product mixture resulting from subsequent reactions of a surface-bound benzenethiyl radical. The optical, electrochemical, and photochemical properties of these clusters thus represent reasonable transition models for the development of colligative properties in moving from very small molecules to the bulk semiconductor.

\section{Acknowledgements}

We are grateful to the German Federal Government (Department of Technology) for support of the student fellowship that permitted T. Türk's work in Austin and to the U.S. Department of Energy, Office of Basic Energy Sciences, for financial support in Texas. We thank F. Sabin for assistance in the synthesis of the clusters and Jon Merkert for assistance in the electrochemical measurements. The reported lifetimes were measured at the Center for Fast Kinetics Research, a facility jointly supported by the National Institutes of Health and the University of Texas. We are grateful to D. J. Kiserow and S. M. Hubig for assistance in the time-resolved measurements. 


\section{References}

1. Fox, M. A. Top. Curr. Chem. 1991, 159, 68.

2. Fox, M. A. In Photocatalysis; Serpone, N.; Pelizzetti, E., Eds.; Academic Press: Orlando, FL, 1989; Chapter 13.

3. Henglein, A. Top. Curr. Chem. 1988, 143, 113.

4. Henglein, A. Chem. Rev. 1989, 89, 1861.

5. Brus, L. E. J. Phys. Chem. 1986, 90, 2555.

6. Steigerwald, M. L.; Brus, L. E. Accts. Chem. Res. 1990, 23, 183.

7. Wang, Y.; Herron, N. J. Phys. Chem. 1991, 95, 525.

8. Stucky, G. D.; MacDougall, J. E. Science 1990, 47, 669.

9. Krishnan, M.; White, J. R.; Fox, M. A.; Bard, A. J. J. Amer. Chem. Soc. 1983, $105,7002$.

10. Kuczynski, J. P.; Miloslavjevic, B. H.; Thomas, J. K. J. Phys. Chem. 1984, 88, 980.

11. Wang, Y.; Suna, A.; Mahler, W.; Kasowski, R. J. Chem. Phys. 1987, 87, 7315.

12. Smotkin, E. S.; Brown, R. M., Jr.; Rabenberg, L. K.; Salomon, K.; Bard, A. J.; Campion, A.; Fox, M. A.; Mallouk, T. E.; Webber, S. E.; White, J. M. J. Phys. Chem. 1990, 94, 7543.

13. Watzke, H. J.; Fendler, J. H. J. Phys. Chem. 1987, 91, 854.

14. Chang, A. C.; Pfeiffer, W. F.; Buillaume, B.; Baral, S.; Fendler, J. H. J. Phys. Chem. 1990, 94, 4284.

15. Wang, Y.; Herron, N. J. J. Phys. Chem. 1988, 92, 4988.

16. Herron, N.; Wang, Y.; Eddy, M. M.; Stucky, G. D.; Cox, D. E.; Moller, K.; Bein, T. J. Am. Chem. Soc. 1989, 111, 530.

17. Persaud, L.; Bard, A. J.; Campion, A.; Fox, M. A.; Mallouk, T. E.; Webber, S. E.; White, J. M. Inorg. Chem. 1987, 26, 3825.

18. Pettit, T. L.; Fox, M. A. J. Org. Chem. 1985, 50, 5013.

19. Dannhauser, T.; O’Neal, M.; Johansson, K.; Whitten, D.; McLendon, G. J. Phys. Chem. 1986, 90, 6074.

20. Spandel, L.; Haase, M.; Weller, H.; Henglein, A. J. Am. Chem. Soc. 1987, 109, 5649.

21. Wang, Y.; Suna, A.; McHugh, J.; Hilinski, E. F.; Lucas, P. A.; Johnson, R. D. J. Chem. Phys. 1990, 92, 6927.

22. Steigerwald, M. L.; Alivasatos, A. P.; Gibson, J. M.; Harris, T. D.; Kortan, R.; Muller, A. J.; Thayer, A. M.; Duncan, T. M.; Douglass, D. C.; Brus, L. E. J. Am. Chem. Soc. 1988, 110, 3046.

23. Nosaka, Y.; Yamaguchi, K.; Miyama, H. Chem. Lett. 1988, 605.

24. Kortan, A. R.; Hull, R.; Opila, R. L.; Bawendi, M. G.; Carroll, P. J.; Brus, L. E. J. Am. Chem. Soc. 1990, 112, 1327.

25. Herron, N.; Wang, Y.; Eckert, H. J. Am. Chem. Soc. 1990, 112, 1322.

26. Dameron, C. T.; Reese, R. N.; Mehra, R. K.; Kortan, A. R.; Carroll, P. J.; Steigerwald, M. L.; Brus, L. E.; Winge, D. R. Nature 1989, 338, 596.

27. Smotkin, E. S.; Lee, C. L.; Bard, A. J.; Campion, A.; Fox, M. A.; Mallouk, T.; Webber, S. E.; White, J. M. Chem. Phys. Lett. 1988, 152, 265.

28. Fischer, Ch. H.; Lilie, J.; Weller, H.; Katsikas, L.; Henglein, A. Ber. Bunsenges Phys. Chem. 1989, 93, 61.

29. Fischer, Ch. H.; Weller, H.; Katsikas, L.; Henglein, A. Langmuir 1989, 5, 429. 
30. Eychmüller, A.; Katsikas, L.; Weller, H. Langmuir 1990, 6, 1605.

31. Fischer, Ch. H.; Weller, H.; Foijtik, A.; Lume-Pereira, C.; Jonata, E.; Henglein, A. Ber. Bunsenges. Phys. Chem. 1986, 90, 46.

32. Kakuta, N.; White, J. M.; Campion, A.; Bard, A. J.; Fox, M. A.; Webber, S. E. J. Phys. Chem. 1985, 89, 48.

33. Mau, A. W. H.; Huang, C. B.; Kakuta, N.; Bard, A. J.; Campion, A.; Fox, M. A.; White, J. M.; Webber, S. E. J. Am. Chem. Soc. 1984, 106, 6537.

34. Kakuta, N.; White, J. M.; Campion, A.; Bard, A. J.; Fox, M. A.; Webber, S. E. J. Phys. Chem. 1985, 89, 48.

35. Lacelle, S.; Stevens, W. C.; Kurtz, D. M.; Richardson, J. W.; Jacobsen, R. A. Inorg. Chem. 1984, 23, 930.

36. Dean, P. A. W.; Vittal, J. J. Inorg. Chem. 1986, 25, 514.

37. Dance, I. G.; Choy, A.; Scudder, M. L. J. Am. Chem. Soc. 1984, 106, 6285.

38. Brennan, J. G.; Siegrist, T.; Stuczynski, S. M.; Steigerwald, M. L. J. Am. Chem. Soc. 1990, 112, 9233.

39. Kunkely, H.; Vogler, A. J. Chem. Soc., Chem. Commun. 1990, 1204.

40. Cardona, R.; Gaillard, E.; Fox, M. A. J. Am. Chem. Soc. 1987, $107,6347$.

41. Fox, M. A. Chem. Rev. 1979, 79, 253.

42. Bahnemann, D. W.; Kormann, C.; Hoffmann, M. R. J. Phys. Chem. 1987, 91, 3789.

43. Bird, B. D.; Day, P. J. Chem. Soc., Chem. Commun. 1967, 741.

44. Vogler, A.; Kunkely, H. J. Am. Chem. Soc. 1986, 108, 7211.

45. Vogler, A.; Kunkely, H. Chem. Phys. Lett. 1989, 158, 74.

46. Vogler, A.; Kunkely, H. Chem. Phys. Lett. 1988, 150, 135.

47. Kunkely, H.; Vogler, A. Chem. Phys. Lett. 1989, 164, 621.

48. Hubig, S. M. J. Lumin. 1991, 47, 137.

49. Hubig, S. M.; Dionne, B. C.; Rodgers, M. A. J. J. Phys. Chem. 1986, 90, 5873.

RECEIVED for review November 7, 1991. ACCEPTED revised manuscript May 11, 1992.

Reprinted from ACS Advances in Chemistry Series No. 238

Photosensitive Metal-Organic Systems: Mechanistic Principles and Applications

Charles Kutal and Nick Serpone, Editors

Copyright @ 1993 by the American Chemical Society

Reprinted by permission of the copyright owner 